\title{
25 Research Square \\ Building a Cancer Coalition: A co-design framework for evaluating regionalism in the South Pacific
}

Amelia Hyatt ( $\sim$ amelia.hyatt@petermac.org )

Peter MacCallum Cancer Centre https://orcid.org/0000-0003-2322-7817

\section{Belinda Chan}

Fiji Cancer Society

Rob Moodie

University of Melbourne School of Population Health: The University of Melbourne School of Population and Global Health

\section{Megan Varlow}

Cancer Council Australia

\section{Chris Bates}

World Health Organization Division of Pacific Technical Support

\section{Sunia Folaki}

Massey University - Wellington Campus

\section{Neal Palafox}

University of Hawai'i at Manoa John A Burns School of Medicine

\section{Shelley Burich}

Samoa Cancer Society

\section{Sanchia Aranda}

Peter MacCallum Cancer Centre

\section{Research}

Keywords: Cancer Control, Western Pacific, Coalition, Partnerships, Framework, Policy

Posted Date: August 3rd, 2021

DOI: https://doi.org/10.21203/rs.3.rs-744839/v1

License: (a) (i) This work is licensed under a Creative Commons Attribution 4.0 International License. Read Full License 


\section{Abstract \\ Background}

Cancer is a significant problem for the South Pacific region due to a range of complex and unique health challenges caused by shared social, environmental and economic factors. Currently gaps in diagnosis, treatment and palliative care are significant, and while governmental commitment is strong, economic constrains limit health system strengthening. Collaboration, alliances and partnerships in cancer control have been successful in resource constrained settings. A regional approach has therefore been recommended as an effective solution to addressing many of the challenges for cancer control in the South Pacific. However, comprehensive and appropriate information detailing how to effectively scope and establish a multi-national or regional coalition is scarce. This study therefore aimed to 1) create a Coalition Development Framework, and 2) use the Framework to co-design a South Pacific Cancer Control Coalition through consultation with key cancer control stakeholders working within Fiji, New Caledonia, Papua New Guinea, Samoa and Tonga.

\section{Results}

Analysis of the consultations with key cancer control stakeholders identified overwhelming appetite and support for a South Pacific Cancer Control Coalition. This paper details the following six coalition development outputs: coalition design and purpose, strategic imperatives, structure, South Pacific foundations, barriers and facilitators to coalition establishment and ongoing operations, priorities for action. Concurrent evaluation of the Coalition Development Framework using theory of change revealed the framework to be an effective mechanism to drive engagement, discovery, unification and action in alliance-building.

\section{Conclusions}

A regional Coalition to drive cancer control in the South Pacific has significant support among key Pacific stakeholders. Likewise, design and scope of the Coalition has been synthesised and mapped to guide feasible and appropriate establishment. Importantly our results also describe the effective implementation of a Coalition Development Framework in an applied setting, to guide future use. If momentum is continued, and a regional South Pacific Coalition established, the benefits in reducing the burden of cancer within the region will be substantial.

\section{Background}

Globally, cancer is one of the leading causes of morbidity and mortality, with rates set to continue to rise worldwide ${ }^{1}$. The Pacific is particularly impacted by non-communicable diseases (NCDs) such as cancer, due to a range of complex and unique health challenges caused by shared social, environmental and 
economic factors ${ }^{2}$. The region comprises 22 Pacific island countries and territories (PICTs) which sit within the geographically and culturally distinct island groupings of Melanesia, Polynesia and Micronesia, with a combined population of approximately 10.5 million ${ }^{2-5}$. The term 'South Pacific' refers to the region and nations located south of the equator. However, the true scale of cancer burden in the South Pacific is difficult to ascertain due to significant challenges with obtaining, measuring and recording accurate diagnostic data ${ }^{2-8}$. The few national cancer registries in existence are cited as fragmented or dormant; with the notable exception of New Caledonia ${ }^{3-7}$.

Factors which drive high rates of cancer within the region include, but are not limited to: geographic remoteness both within and between PICTs; high rates of cancer risk factors such as obesity, and tobacco and alcohol use; strong influence from unhealthy commodity industries; food insecurity and lack of access to healthy produce; fragile developing economies; and impacts from climate change ${ }^{2-5,7-10}$. In addition, many PICTs are undergoing epidemiological transition, meaning communicable disease risk factors are still highly prevalent ${ }^{3,4,11}$. Together, these factors create a challenging setting for governments in the establishment of effective cancer control policy, infrastructure, workforce and activity $^{2,5,10}$.

Many PICTs in the South Pacific are unable to provide adequate treatment or palliative care services for people diagnosed with cancer ${ }^{3-5,12,13}$. Patients often cannot access chemotherapy, or even analgesics that are on the World Health Organization's (WHO) essential medicines list ${ }^{4,13,14}$. Provision of basic cancer care in low resource settings still requires speciality services, highly trained workforce, and costly infrastructure and consumables ${ }^{15-17}$. While strengthening cancer treatment is on the policy agenda for many governments within the region, economic constraints are cited as the key barrier ${ }^{2,18}$. Small population sizes in many PICTs further limit the feasibility of implementation of such specialist services at a national level ${ }^{2,4}$. Population health screening, as a key cancer control activity, can increase survival for breast, colon and cervical cancers ${ }^{15,18}$, however, the majority of South Pacific countries do not have adequate histopathology services to diagnose and stage cancer, meaning that many cases are unable to be detected or correctly diagnosed ${ }^{3-5,8}$. Further, without adequate treatment, diagnosis can create an ethical dilemma ${ }^{19}$. As noted, cancer risk factors are prevalent in the South Pacific, however population health literacy regarding cancer risks and identification of symptoms remains low ${ }^{13,20,21}$.

A regional, collaborative approach has been recommended as an effective solution to addressing many of the challenges for cancer control in the South Pacific ${ }^{4,5}$. Collective approaches, such as coalitions or other voluntary multi-stakeholder agreements created to improve mutually agreed healthcare goals, have been demonstrated to be effective and feasible in many settings around the world ${ }^{13,17,22,23}$. Diverse multi-sectoral and multi-national partnerships are likewise considered essential by both the WHO and Union for International Cancer Control when developing and implementing comprehensive cancer control plans and strategies ${ }^{17,24}$. In the Pacific there exists precedence for regional comprehensive cancer control planning. The United States of America (USA) Centre for Disease Control and Prevention (CDC) 
funded the establishment of the Cancer Council of the Pacific Islands (CCPI) to facilitate a regional multinational coalition of all USA-affiliated Pacific island jurisdictions in the early $2000 \mathrm{~s}^{25-28}$. Since its inception, the CCPI has successfully developed effective cancer control strategies for the USA-affiliated islands, including national and regional registry establishment, population cancer screening, and workforce capacity development ${ }^{25-28}$. However, despite the existence of successful regional healthfocused alliances, comprehensive and appropriate information detailing how to effectively scope and establish a multi-national or regional coalition is scarce.

This project consisted of two parts: 1) the creation of the Coalition Development Framework, and 2) use of the Framework to co-design a South Pacific Cancer Control Coalition through consultation with key cancer control stakeholders working within Fiji, New Caledonia, Papua New Guinea, Samoa and Tonga. Project aims comprised: i) determine interest for a regional South Pacific Cancer Control Coalition, ii) identify essential requirements for successful Coalition establishment and ongoing sustainability, iii) confirm national and regional cancer control priority areas, barriers and facilitators, and iv) collate learnings to inform continued use of the Framework to develop cancer control coalitions.

\section{Methods}

Pacific leadership and oversight

Importantly, the drivers for this project were key civil society organisations (CSOs) based in Fiji and Samoa: the Fiji Cancer Society (FCS) and Samoa Cancer Society (SCS) who contacted SA as CEO of Cancer Council Australia (CCA) and through this AH undertook this work as part of her Master of Public Health Studies with the University of Melbourne. FCS and SCS also work in close partnership with national Ministries of Health, tertiary and primary healthcare services, and other health and cancerspecific non-government organisations to deliver cancer control services in the Pacific. Given the challenges and limitations faced by these nations regarding cancer control, the FCS, SCS and CCA are committed to investigating and supporting a regional approach within the South Pacific.

\section{Pacific Project Advisory Committee}

A Pacific project advisory committee was established prior to the commencement of this project to provide stakeholder input into the design and operations of this study. The committee comprised members from the FCS, SCS and additional cancer control specialists with experience in regionalism and coalition-building based in Fiji, Samoa, New Zealand, Hawaii and Australia. This group was responsible for ensuring Pacific leadership, oversight, and input into: project and Framework design, data collection and analysis, and project reporting and dissemination.

Creation of the Coalition Development Framework

The first step in creation of the Coalition Development Framework comprised determining and assessing relevant materials currently in existence. A scoping review of publications describing the elements, 
processes, and activities required for the establishment and ongoing success of operational health coalitions and multi-stakeholder partnerships was conducted. This review identified a small number of peer reviewed journal articles and one white paper publication. Content analysis of these documents identified a range of key elements and activities which informed the Coalition Development Framework (see Table 1.) 
Table 1

Key sources informing coalition framework development

\section{Source / Author}

Toolkit: "Practical guide on how to build effective NCD alliances"

NCD Alliance $(\mathrm{NCDA})^{29}$

Journal Article: A socio-ecological framework for cancer control in the Pacific: a community case study of the US affiliated Pacific Island jurisdictions

Neal A Palafox et. al ${ }^{27}$

\section{Elements}

Define coalition need, scope the landscape, make the case for partnership, develop a shared agenda, determine design and governance
Use

Useful in identifying key practical elements, activities and stages for the development of health alliances
Journal Article: Cancer control in small island nations: from local challenges to global action

Diana Safarti et al ${ }^{2}$ Journal Article: Multistakeholder partnerships: breaking down barriers to effective cancercontrol planning and implementation in low-and middleincome countries
Determine organisational design, stakeholder inclusion, managing power-brokers and civil society engagement and leadership
Provided important learnings for operationalising key concepts in coalition establishment
Political will, support from health leaders, individual country resources and needs are identified, mutually agreed governance structures are developed, ongoing review processes established, collaborative leadership and decision-making, priorities determined

Recommendations that interested stakeholders form teams to complete situational analyses and engage with international partners to provide technical support in developing action plans
Recommendations for essential elements associated with ongoing success of regional partnership and alliances, particularly at the country-level are important to consider and include in coalition building

Theoretical underpinnings guiding effective development of multistakeholder partnerships in cancer control planning and implementation are useful for informing and guiding the development of framework inputs, activities and outputs

\section{Paul Pearlman et al ${ }^{17}$}

Journal Article:

Pacific island partnership: the Pacific Cancer Initiative

Neal A Palafox et. $\mathrm{al}^{28}$
Identifies that a participatory development process is essential for success, needs assessments to determine contextual factors for consideration are important, diversity is an important strength of multistakeholder partnerships
Provided evidence that codevelopment and design of a coalition with input from all relevant and appropriate stakeholders is essential to ensure operational success 


\begin{tabular}{|c|c|c|}
\hline Source / Author & Elements & Use \\
\hline $\begin{array}{l}\text { Journal Article: Cancer } \\
\text { control in the Pacific: } \\
\text { A South Pacific } \\
\text { collaborative } \\
\text { approach } \\
\text { Sunia Foliaki et al }\end{array}$ & $\begin{array}{l}\text { Proposes a model of regional } \\
\text { cooperation in the South Pacific } \\
\text { terms of functionality, key steps (e.g. } \\
\text { establishing leadership, undertaking } \\
\text { needs assessments), potential } \\
\text { collaborators, and highlights cancer } \\
\text { control strenathening opportunities }\end{array}$ & $\begin{array}{l}\text { Provides support for a CSO-led } \\
\text { coalition model, outlines ideas for } \\
\text { steps and opportunities which } \\
\text { triangulate and harmonise with } \\
\text { other coalition-building sources }\end{array}$ \\
\hline
\end{tabular}

Identified elements and activities were then synthesised into the proposed Coalition Development Framework using program logic. The Coalition Development Framework is proposed as a comprehensive, evidence-informed step-by-step guide to assist leading stakeholders in the design and development of health coaltions (see Table 2). Four key phases across all resources and materials were identified as essential: Engagement; Discovery; Unification, and Action (see Fig. 1).

The Engagement phase focuses on stakeholder engagement, Discovery focuses collection of information and stakeholder perspectives, Unification focuses on synthesis of ideas into coalition design drafting and planning, and Action refers to finalisation of coalition structure and determination of strategic priorities. Each phase includes a dedicated aim and associated deliverables in the form of discrete activities and outputs recommended for completion, from conducting a situational analysis to a proposed coalition organisational design and model. Importantly, once commencing, each phase should continue until the Coalition is established, as activities and processes are non-linear, and involve iterative and continuous connection to facilitate development, information synthesis and consensus-building (described in Table 2). 
Table 2

Coalition Development Framework Outline

\begin{tabular}{|c|c|c|c|c|}
\hline Phase & Aim & Category & $\begin{array}{l}\text { Deliverables to } \\
\text { complete }\end{array}$ & Elaboration \\
\hline \multirow[t]{6}{*}{ Engagement } & \multirow[t]{6}{*}{$\begin{array}{l}\text { Determine all } \\
\text { relevant } \\
\text { individual and } \\
\text { organisational } \\
\text { activity within } \\
\text { the region }\end{array}$} & \multirow[t]{4}{*}{ Activities: } & \multirow{2}{*}{$\begin{array}{l}\text { ÿ Complete a } \\
\text { comprehensive } \\
\text { situational analysis } \\
\text { to identify all } \\
\text { individual and } \\
\text { organisational } \\
\text { activity within the } \\
\text { area of interest }\end{array}$} & $\begin{array}{l}\text { Once commenced, } \\
\text { stakeholder engagement, } \\
\text { should continue throughout } \\
\text { all stages of Coalition } \\
\text { development. }\end{array}$ \\
\hline & & & & \multirow{5}{*}{$\begin{array}{l}\text { Likewise, the situational } \\
\text { analysis should continue to } \\
\text { be updated as new } \\
\text { information is collected and } \\
\text { synthesised. }\end{array}$} \\
\hline & & & $\begin{array}{l}\text { ÿ Define key } \\
\text { stakeholders and } \\
\text { commence } \\
\text { stakeholder } \\
\text { engagement to } \\
\text { determine } \\
\text { preliminary Coalition } \\
\text { interest }\end{array}$ & \\
\hline & & & $\begin{array}{l}\text { ÿ Use stakeholder } \\
\text { contacts to identify } \\
\text { other potential } \\
\text { actors for } \\
\text { engagements }\end{array}$ & \\
\hline & & Outputs: & $\begin{array}{l}\text { ÿ A preliminary } \\
\text { situational analysis: } \\
\text { covering all key } \\
\text { actors in all sectors } \\
\text { (state, market, civil } \\
\text { society) }\end{array}$ & \\
\hline & & & ÿ Stakeholder lists & \\
\hline
\end{tabular}




\begin{tabular}{|c|c|c|c|c|}
\hline Phase & Aim & Category & $\begin{array}{l}\text { Deliverables to } \\
\text { complete }\end{array}$ & Elaboration \\
\hline \multirow[t]{7}{*}{ Discovery } & \multirow[t]{7}{*}{$\begin{array}{l}\text { Continue to } \\
\text { build } \\
\text { knowledge } \\
\text { and } \\
\text { momentum } \\
\text { from the } \\
\text { Engagement } \\
\text { phase. }\end{array}$} & \multirow[t]{4}{*}{ Activities: } & $\begin{array}{l}\ddot{y} \text { Continued } \\
\text { stakeholder } \\
\text { engagement via } \\
\text { more structured and } \\
\text { purposeful } \\
\text { consultation } \\
\text { ÿ Confirmation of } \\
\text { information } \\
\text { identified in the } \\
\text { situational analysis / } \\
\text { updating of } \\
\text { situational analysis } \\
\text { as new information } \\
\text { is gathered }\end{array}$ & \multirow[t]{7}{*}{$\begin{array}{l}\text { Formal or informal interviews } \\
\text { or conversations can be } \\
\text { employed to connect with key } \\
\text { stakeholders. Ideally, as } \\
\text { information in the } \\
\text { Engagement and Discovery } \\
\text { phase is collected and } \\
\text { documented, regular, iterative } \\
\text { review and synthesis should } \\
\text { be undertaken. }\end{array}$} \\
\hline & & & $\begin{array}{l}\text { ÿ Verification of } \\
\text { coalition interest, } \\
\text { and level of } \\
\text { commitment to } \\
\text { involvement and } \\
\text { ongoing action }\end{array}$ & \\
\hline & & & $\begin{array}{l}\ddot{y} \text { Initial identification } \\
\text { of contextual } \\
\text { information e.g. } \\
\text { barriers and } \\
\text { potential threats } \\
\text { versus facilitators } \\
\text { and existing } \\
\text { strengths }\end{array}$ & \\
\hline & & & $\begin{array}{l}\text { ÿ Preliminary } \\
\text { suggestions for } \\
\text { Coalition design, } \\
\text { structure, purpose } \\
\text { and goals are } \\
\text { identified }\end{array}$ & \\
\hline & & \multirow[t]{3}{*}{ Outputs: } & $\begin{array}{l}\ddot{y} \text { Updated } \\
\text { situational analysis }\end{array}$ & \\
\hline & & & $\begin{array}{l}\text { ÿ Stakeholder } \\
\text { analysis confirming } \\
\text { interest and } \\
\text { engagement in a } \\
\text { Coalition }\end{array}$ & \\
\hline & & & $\begin{array}{l}\text { ÿ Several } \\
\text { draft/potential } \\
\text { models for Coalition } \\
\text { design, structure, } \\
\text { purpose and goals }\end{array}$ & \\
\hline
\end{tabular}




\begin{tabular}{|c|c|c|c|c|}
\hline Phase & Aim & Category & $\begin{array}{l}\text { Deliverables to } \\
\text { complete }\end{array}$ & Elaboration \\
\hline \multirow[t]{7}{*}{ Unification } & \multirow{7}{*}{$\begin{array}{l}\text { Achieve unity } \\
\text { and } \\
\text { consensus on } \\
\text { key issues, } \\
\text { such as } \\
\text { context, } \\
\text { proposed } \\
\text { Coalition } \\
\text { design and } \\
\text { structure. }\end{array}$} & Activities: & $\ddot{y}$ & \multirow{7}{*}{$\begin{array}{l}\text { Discussion and testing of } \\
\text { popular concepts and ideas } \\
\text { with engaged stakeholders is } \\
\text { important as key ideas begin } \\
\text { to coalesce and form more } \\
\text { concrete structures. At the } \\
\text { end of this phase, a clear } \\
\text { outline of the Coalition } \\
\text { design, structure and purpose } \\
\text { should be evident. }\end{array}$} \\
\hline & & & $\begin{array}{l}\text { ÿ Continued } \\
\text { stakeholder } \\
\text { engagement and } \\
\text { consultation }\end{array}$ & \\
\hline & & & $\begin{array}{l}\text { ÿ Updating of } \\
\text { situational analysis } \\
\text { as new information } \\
\text { is gathered }\end{array}$ & \\
\hline & & & $\begin{array}{l}\text { y Synthesising of } \\
\text { information to group } \\
\text { key ideas and } \\
\text { themes }\end{array}$ & \\
\hline & & & $\begin{array}{l}\text { ÿ Building } \\
\text { consensus on key } \\
\text { issues and concepts }\end{array}$ & \\
\hline & & Outputs: & $\begin{array}{l}\ddot{y} \text { Updated } \\
\text { situational analysis }\end{array}$ & \\
\hline & & & $\begin{array}{l}\text { ÿ One or two } \\
\text { possible plans for } \\
\text { Coalition design, } \\
\text { structure, purpose } \\
\text { and goals }\end{array}$ & \\
\hline \multirow[t]{4}{*}{ Action } & \multirow[t]{4}{*}{$\begin{array}{l}\text { Finalise all } \\
\text { essential } \\
\text { Coalition } \\
\text { concepts }\end{array}$} & Activities: & $\begin{array}{l}\text { ÿ Finalise Coalition } \\
\text { design, strategy and } \\
\text { structure }\end{array}$ & \multirow{4}{*}{$\begin{array}{l}\text { The Action phase should } \\
\text { continue until shared vision is } \\
\text { established, and all } \\
\text { stakeholders agree on } \\
\text { Coalition development } \\
\text { concepts and future plans. }\end{array}$} \\
\hline & & & $\begin{array}{l}\text { ÿ Determine strategic } \\
\text { imperatives, key } \\
\text { milestones and } \\
\text { priorities for action }\end{array}$ & \\
\hline & & & $\begin{array}{l}\text { ÿ Consolidate all } \\
\text { findings into a report } \\
\text { for stakeholder } \\
\text { review and } \\
\text { ratification }\end{array}$ & \\
\hline & & Outputs: & $\begin{array}{l}\text { ÿ A proposed model } \\
\text { for Coalition design, } \\
\text { structure, purpose } \\
\text { and goals, including } \\
\text { indicative funding } \\
\text { sources and plans } \\
\text { for financial } \\
\text { sustainability, } \\
\text { endorsed by the } \\
\text { majority of engaged } \\
\text { stakeholders }\end{array}$ & \\
\hline
\end{tabular}


Co-design Consultations South Pacific

Once created, the Coalition Development Framework was used to co-design the establishment of a South Pacific Cancer Control Coalition. Evaluation of the Framework in this applied setting was documented using Interpretive Description and health program evaluation research methods ${ }^{30}$.

Co-design was employed as the overarching methodology to support coalition development, as the principles and practical application of co-design require active and democratic involvement of a diverse range of participants from concept creation to implementation of solutions developed in response to shared challenges ${ }^{31}$. In particular, co-design has been recognised as a novel methodology increasing useful for engaging stakeholders to find solutions to complex problems, particularly in the policy context ${ }^{31}$.

Data collection occurred over six weeks from September 10th to October 29th, 2019. During this time, the research team were based in Fiji with the FCS as they commenced stakeholder consultations, and travelled to Tonga and Samoa to meet with participants face-to-face for interviews. Participants located in New Caledonia and Papua New Guinea were contacted via videoconference.

\section{Consultations}

Stakeholders working in a cancer control-related role at either a national or regional level in the following organisations were identified through the project advisory committee as potential Coalition partners:

- National Cancer-specific civil society organisations (CSOs) or non-government organisations (NGOs)

- Ministry or Department of Health

- Health Services (primary/tertiary/community/public/private)

- Regional Development Partners

The project advisory committee invited all identified stakeholders to take part in a consultation to share their perspectives regarding the establishment of a cancer control coalition for the region. If the stakeholder was interested in discussing a regional Coalition an interview time was arranged.

Informed consent

As the project concurrently involved evaluation of the coalition framework, potential participants were also emailed with a research participant information and consent form (PICF). At the time of the interview, if the participants agreed for their interview data to form part of the research study, they were asked to sign a copy of the consent form and were given a copy to keep.

\section{Evaluation}


A semi-structured interview schedule was developed to facilitate evaluation of the framework, with 12 questions and associated prompts mapping to the four stages within the Coalition Development Framework of engagement, discovery, unification and action. Stakeholders who agreed to participate in the research project had their consultations audio-recorded and then transcribed to facilitate analysis.

\section{Field notes}

Comprehensive notes were created to supplement interview data and to document information relevant to evaluation of the Coalition Development Framework.

Demographic data

Three demographic questions were also included at the start of the interview comprising participant role, organisation type, and country of focus.

\section{Data Analysis}

\section{Quantitative data}

Demographic data were analysed descriptively, using means and standard deviations, or frequencies and percentages where appropriate.

\section{Qualitative data}

Consultation transcripts and other text documents (field notes etc.) were uploaded to NVIV012 for analysis using interpretive description methods ${ }^{32}$. Consultations were analysed in alignment with the Coalition Development Framework phases to facilitate evaluation. Analysis was inductive, with data initially described in broad, generic codes, which were then iteratively and reflexively re-labelled and interpreted as categories and themes were developed ${ }^{18}$. Analysis was considered finalised once themes reached a balance of both meaningfully representing stakeholder perspectives, and addressing the research objectives ${ }^{33}$.

\section{Results}

\section{Engagement}

A total of 43 stakeholders working directly within cancer control, and other key leaders or actors ancillary or adjacent to cancer control within the health or government sector were identified and contacted. Of these, 35 were available and interested in taking part in a consultation to discuss a South Pacific Regional Coalition, and all were happy to participate in the research evaluation of the framework. Table 3 summarises the key characteristics of stakeholders interviewed. Role title and organisation name are not reported to preserve participant confidentiality.

Table 3: Summary of stakeholder demographic characteristics 


\begin{tabular}{lll} 
Stakeholder Demographic Category & $n$ & $\%$ \\
\hline Role & & \\
\hline Public Health Professional & 11 & 31 \\
\hline Clinician & 9 & 26 \\
\hline Policymaker & 6 & 17 \\
\hline Project/Technical Officer & 5 & 14 \\
\hline Epidemiologist & 2 & 6 \\
\hline Consumer Advocate & 1 & 3 \\
\hline Academic & 1 & 3 \\
\hline Organisation type & & \\
\hline CSO/NGO & 11 & 31 \\
\hline Ministry/Department of Health & 9 & 26 \\
\hline Development Partner & 6 & 17 \\
\hline Public Tertiary Health Service & 4 & 11 \\
\hline Private Tertiary Health Service & 3 & 9 \\
\hline Private Primary Care Health Service & 1 & 3 \\
\hline Academic Organisation & 1 & 3 \\
\hline Country Focus & & \\
\hline Fiji & 15 & 43 \\
\hline Regional & 8 & 23 \\
\hline Tonga & 5 & 14 \\
\hline Samoa & 3 & 11 \\
\hline New Caledonia & 6 \\
\hline Papua New Guinea & & \\
\hline
\end{tabular}

The majority of the stakeholder consultations ( $n=29,83 \%)$ were conducted face-to-face in country; the remainder were conducted via telephone or videoconference $(n=6,17 \%)$. Consultations ran for an average of forty-two minutes (SD = 20mins), generating a total of twenty-three hours of data. Of the eight stakeholders identified but not consulted: three were on leave for the duration of the project, three did not 
respond to emails, one did not have time-capacity (though was supportive of the project), and one was cancelled due illness and was unable to be rescheduled.

\section{Discovery, unification and action}

Analysis of the consultations identified the following six coalition development outputs:

1. Coalition design and purpose

2. Strategic imperatives

3. Structure

4. South Pacific foundations

5. Barriers and facilitators to coalition establishment and ongoing operations

6. Priorities for action

Diagrams were developed to summarise and describe each stakeholder output, with a composite of all outputs diagrams presented in Figure 2. A comprehensive situational analysis was completed and will be reported elsewhere. Development of the finalised coalition model will also be reported elsewhere. .

\section{Output 1: Coalition Design and Purpose}

All thirty-five stakeholders supported the development of a South Pacific Cancer Control Coalition. Stakeholders suggested the first step in the development of the Coalition should be the establishment of a central hub or secretariat, such as a regional Cancer Agency. This would reduce the burden of administration, management, or potential perceived 'ownership' from any one country.

"When we seek to meet, we should all know what we're working towards. We should all have the same vision, the same mission." Participant 14

Eliminate Cancer or a Cancer-Free Pacific were suggested vision statement, however other stakeholders preferred a more results-oriented and achievable purpose statement, such as: Effective Cancer Control (see figure 2). Values specified by stakeholders included: Transparency, Accountability, Respect and Integrity. Stakeholders also emphasised that the Coalition must be outcomes focused, and result in tangible and measurable benefits for the people and communities suffering from cancer. The Coalition would consist of all interested South Pacific organisations currently working in cancer control and be open to new members over time. For organisations to become part of the Coalition, their mission and values would need to be aligned with those of the Coalition.

\section{Output 2: Strategic Imperatives}

Stakeholders agreed that the Coalition will need to have a clear mandate, purpose, and objectives. These will be essential to ensure that the Coalition is effective and not passive or tokenistic. The following 
strategic imperatives articulate both key objectives, and what individuals and organisations would expect from membership (see Figure 2).

\section{Partnerships}

Facilitate community and regional networks, and foster partnerships between individuals and organisations.

\section{Data-driven to respond to South Pacific needs}

Respond to issues identified through data collected by members in region-specific clinical settings and by cancer registries.

\section{Cancer-specific, long term and sustainable change}

Increase the visibility of cancer in the South Pacific. An established coalition to assist CSOs leverage long-term and comprehensive health system change.

\section{Advocacy and Empowerment}

Provide a powerful, unified, and respected voice to the political arena to bring cancer to the forefront of discussions; and empower national agencies in advocating in the international setting.

"This Coalition can be a source of empowerment to the national agencies on cancer prevention, cancer treatment diagnosis, cancer medicine" Participant 4

\section{Sharing and Capacity-building}

Enable accurate information about cancer care organisations, technical expertise, facilities, and healthcare workforce to be effectively shared and communicated throughout the region.

A regional approach to cancer control would increase regional capacity, knowledge, and resources.

\section{Strengthen, complement, streamline}

Enable a strategic approach to all activities from education, awareness, and outreach, through to screening, treatment, and palliative care. All current activities would be strengthened and streamlined through partnerships and coordination.

\section{Output 3: Structure and Membership}

Stakeholders agreed that Coalition membership would be open to all South Pacific island states and all cancer and health-focused organisations, departments or services interested in participation (figure 2). Most stakeholders felt that the Coalition should be CSO-driven. It was recommended that the Coalition work in tandem with governments and clinical services, but noted that CSOs have the potential to act 
independently, call government actors to account, and can potentially overcome or bypass political or diplomatic issues between countries.

"It will need to be a strong body that ministries or governments are answerable to" Participant 32

\section{Representative of all working in cancer control}

The Coalition should be representative of each country, and all cancer control activities within the region. The following groups are important for invitation and inclusion:

- Ministries/departments of health

- CSOs and NGOs

- Clinical Services and Health Professionals

- Academics

- Consumer advocates

- Traditional Medicine Providers

- Church and other social groups

\section{Partnering with Governments}

For the Coalition to be viable, it would need to work hand in hand with governments and receive endorsement from governments and Heads of Health at a national and regional level.

\section{Supported by Development Partners}

International development partners within the region (such as WHO, SPC or UNICEF) were considered essential for impact and regional cohesion. It was also felt that these organisations would be well placed to provide valuable support for the Coalition in the form of technical and practical assistance.

\section{Theme 4. Maintaining South Pacific Ownership}

\section{Run by and within the South Pacific}

To enable the region to grow and develop, stakeholders strongly felt that Pacific peoples need to be given ownership and leadership positions within the Coalition. Stakeholders emphasised that South Pacific island culture, cancer burden and politics are best understood and navigated by local people.

\section{Maintain Independence}

Stakeholders agreed that the Coalition should maintain independence and sit outside the governmental and clinical arenas. Impartiality and distance were seen as essential in order to effectively set policies, evaluate activities, and work in partnership with governments, health professionals and health services. 
"My observations and my working with different programs or projects have found that there's always a lot of emphasis on bringing external consultants. But I feel to work as a program, it needs to sit with a country; and discover how the country can develop their own capability." Participant 12

\section{Strong Leadership}

A steering committee to drive leadership and governance was suggested, comprising representatives from cancer organisations and health services. A pre-defined time-period for serving on the committee would ensure that people were willing to take on this role, and to nurture innovation and change.

\section{Dedicated paid staff}

Given current capacity constraints faced by all individuals working in cancer in the South Pacific, stakeholders emphasised the need for full-time, paid local staff able to focus solely on the Coalition. However, voluntary assistance and technical support in the development and running of the coalition were recommended as an opportunity to grow South Pacific capacity without jeopardising ownership.

\section{Output Five: Barriers and facilitators to coalition establishment and ongoing operations}

Potential barriers and threats to coalition development and activities were outlined by stakeholders to highlight the challenges which need to be thoughtfully considered, discussed, and addressed. Equally, existing and potential future facilitators were also described, so that development of the coalition can leverage or harness these opportunities where possible and appropriate (see Table 4).

"The big challenge with any kind of any network or coalition, whether within country or across countries is keeping it going. Everybody's fired up at the beginning, but nobody has time to do because everybody's very busy. And nobody's willing to put the time into doing it. And so gradually, it fades away." Participant 16

Table 4: Comparison of barriers and facilitators 


\section{Health system design and cancer burden}

Health systems, cancer burden, risk factors and technical capacity in the region are similar, forming strong facilitators for regional activity and transferrable learnings.

\section{Established multi-national programs and goals}

Existing international indicators, goals and programs can be leveraged by the Coalition to facilitate governmental support, international funding, partnerships, and national accountability.

\section{Established relationships, interest and capacity}

Existing partnerships between CSOs, Ministries of Health and public and private healthcare services can be developed and strengthened with the introduction of a Coalition.

\section{Embracing technology}

Use of technology can be employed by the Coalition to overcome geographical and travel limitations, support health professional networks, telehealth, capacity development; and communication with international partner organisations.

\section{Lack of adequate data}

Paucity of health and cancer-related data in all countries is a significant barrier to Coalition establishment and development of targeted cancer control activities.

\section{Lack of dedicated CSOs or government teams}

No governments in the South Pacific have dedicated cancer teams. Many nations do not have dedicated cancer CSOs. This will be challenging for the Coalition to navigate relationships with governments, and maintain cancer-specific activity.

\section{Politics}

Existing political alliances or issues between nations and regions require the coalition maintain neutrality. Concerns regarding inter-organisational politics and agendas are also present.

\section{Sustainability, funding and travel}

Funding is scarce and existing CSOs and governments are wary of new competitors. Travel can be prohibitively expensive in the Pacific, and logistically difficult as many countries do not have direct transit routes.

\section{Output 6. Priorities for Action}

Experts agreed that priority areas for the coalition must hit a balance between what is meaningful for patients and healthcare professionals, but achievable for NGOs/CSOs or health services and systems. The following priorities were identified as being essential for concurrent health system strengthening across the cancer control continuum:

1. Develop Standardised Systems for Quality Data: Stakeholders agreed that a priority is to establish high quality methods to facilitate data collection, monitoring and evaluation, storage, sharing and research at national and regional levels.

2. Strengthen Prevention and Early Detection: It was unanimously agreed that the Coalition should work to capitalise on momentum and build on current progress in implementation of evidence-based interventions in cancer prevention, and screening for early detection in areas of need, such as cervical cancer.

3. Development of Cancer Control Plans and Policy: development of national and regional cancer control strategy and reviewing and improving current cancer control laws and policies in member 
states.

4. Implementation of Palliative Care Strategy: Stakeholders articulated the dearth of palliative care services currently available and prioritised the development of regional and national palliative care policies and implementation strategies.

5. Improve Overseas Treatment Referral Pathways: Facilitate equitable, affordable, sustainable and appropriate access to cancer treatment within the Pacific (e.g. in New Caledonia, Australia and New Zealand).

6. Pooled Procurement of Anti-Cancer Drugs: Investigate the potential for a regional approach for the procurement and management of anti-cancer drugs.

\section{Framework Evaluation}

Logic model mapping determined that the proposed framework inputs and activities comprising situational analysis, stakeholder consultations, information synthesis and consensus building resulted in the anticipated outputs and outcomes (see figure 3). As stakeholder ideas for Coalition strategy, structure and purpose began to take shape, these were then discussed as part of the ongoing consultation process. New information and perspectives were iteratively incorporated until concrete ideas were finalised, and consensus reached.

Importantly essential considerations regarding use of the framework were identified through this evaluation process. Specifically, diversity of stakeholders and key actors within civil society, the private sector and the state was needed to optimise contextual understanding, and to determine priorities which ensure a whole-of-system approach. Each stakeholder grouping carried unique perspectives and situational understanding which would have been missed if diversity in stakeholders was not purposively sought. Likewise identification of key actors and power-brokers was important, especially to inform targeted engagement where appropriate. In some nations, hierarchy and ceremony are necessary contextual elements to understand and adhere to, particularly as some stakeholders will find it inappropriate to engage unless formal, culturally-specific processes are followed. Identification and engagement with diverse stakeholders and key actors also ensured that the proposed governance and organisational design is inclusive of all interested stakeholders; and accounts for managing or leveraging commercial interest and/or competing priorities.

Early conversations with key stakeholders regarding leadership and ownership were also important. For many people, understanding that the FCS were the key drivers for this work, and that Pacific leadership and ownership was planned and valued, facilitated their engagement and support. Further, as information regarding proposed coalition structure, purpose and design became clear, mechanisms for action were likewise able to be articulated, as leadership and ownership had been to some degree decided upon.

Other key findings highlighted that concurrent mapping of key barriers and facilitators ensured that activities are relevant, achievable and measurable, and so issues could be discussed with relevant actors 
to ensure importation into both organisation design and identification of priorities for action. Finally, including discussion regarding establishment and implementation of monitoring and evaluation frameworks also meant that these key elements were included as essential elements of coalition design rather than as an afterthought.

\section{Discussion}

Stakeholder consultations and perspectives provided comprehensive information to support the feasibility of a South Pacific Cancer Control Coalition and confirmed the appropriateness and usefulness of the proposed Coalition Establishment Framework. Key barriers and facilitators were outlined, and stakeholders described in detail current cancer control activities, and their perceptions regarding priority actions for the Coalition in strengthening cancer control for the region.

\section{Coalition Design: South Pacific and civil society leadership}

Consensus between stakeholders was that this should be a CSO-led Coalition, was formalised as part of the operational design. Interestingly, research looking at regionalism in cancer control for the South Pacific has previously focused only on policy-makers as prime candidates for leadership, agenda setting and decision-making; with CSOs and NGOs included only in relation to their use in the delivery of priority actions ${ }^{2}$. While understandable as health activities are usually led by governments, this is not reflective of the situation in the Pacific, where a large proportion of cancer control activity is being undertaken by civil society, particularly in communities where treatment is not available 5 . Established CCPI and NCDA Coalitions emphasise that civil society leadership has been crucial in their success, and that identification of regional priorities is best commenced where change is aimed to occur, at the community level ${ }^{13}$, 27. Ensuring community is at the heart of all coalition activities from identification of priorities to capacity building to advocacy, has been further cited by several other island nation health coalitions as a key factor behind their success $23,26,27,34$. Civil society can also be highly effective and influential at a policy level in cancer control advocacy and universal health system strengthening ${ }^{35}$. Linking back to the Coalition Development Framework, these findings emphasise the importance of stakeholder determination of leadership, organisational design, and governance in ensuring alignment with local context (figure 3).

Building local health capacity and allowing organisations and nations to remain autonomous was likewise emphasised by stakeholders; a message consistently reiterated in the literature by those working in health within the Pacific ${ }^{5,28,36}$. Underpinning these messages is an issue unfortunately arising in low and middle income countries (LMIC), where global health programs eschew local expertise due to issues such as long-standing colonialist attitudes or belief in the superiority of western knowledge and methods ${ }^{37}$.The CCPI highlights that the essential element behind their success was ensuring that dedicated Pacific staff were hired and appropriately paid to run the Coalition ${ }^{26}$. From these learnings it's clear that assistance provided by development partners in supporting the Coalition must acknowledge 
past issues of colonisation, respect Pacific local knowledge, leadership and decision-making, and ensure funding is directed to ensuring Pacific islanders are recruited to key coalition roles. Dedicated and highly qualified Pacific personnel with strong knowledge of local culture and context will be needed to achieve robust scientific excellence in coalition activities.

\section{Coalition Purpose: Managing politics and power}

Managing potential government desire to lead or override CSO agenda-setting, as documented in other health Coalitions, are important considerations when designing the Coalition organisational design and structure $^{17,27}$. This was noted by stakeholders as a key potential barrier in Coalition establishment for the South Pacific. Harmonising national priorities with regional Pacific coalition priorities has proven difficult in other contexts such as the Alliance of Small Island States in advocating for climate change, where differences in country versus regional agendas limited action on key issues ${ }^{38}$. Therefore coalition goals must be broad enough to facilitate regional action, yet still allow for connectedness with individual state and national goals and strategies. Regionalism requires support from health leaders (both government and private sector) in all countries involved, as these leaders are skilled at identifying and advocating for what is needed in the Pacific context, and little momentum is likely to occur without their support 2, 5, 17, 36. Likewise ensuring that proposed agendas are realistic and well-aligned with governments is important. However, management of power imbalances, or existing political issues, particularly in terms of agendasetting is an important consideration ${ }^{17,38}$. Levels of political influence and power can impact a nation or organisation's ability to effectively bargain or advocate for their needs, and poor political relationships can impact on successful collaborative decision-making ${ }^{17,38}$. Learnings from the CCPI highlighted that good leadership utilises a collaborative partnership structure, which will be important to consider when creating organisational design to ensure that stakeholder relationships remain cohesive and integrated across all hierarchies, systems and cultures, and to overcome potential power imbalances or political issues $^{26,27}$.

\section{Shared Context: overcoming barriers by maximising existing strengths}

Acquiring funding is challenging in a multi-national environment, and as identified, the coalition is likely to be seen as a competitor for resources within an already scarce funding environment ${ }^{27}$. However, capitalising on identified facilitators, such as existing and diverse stakeholder relationships, can widen the range of funding opportunities outside of usual health avenues ${ }^{17}$. Likewise innovative use of technology can overcome multiple sustainability issues such as: travel, funding, and workforce capacity barriers endemic to the Pacific ${ }^{2}$. Health technologies such as telehealth provide evidence-based solutions to bridge the gap, by facilitating access for patients to healthcare irrespective of geographic location ${ }^{39}$. Other initiatives, such as project ECHO, which use video-conferencing and other online communication platforms to facilitate clinician capacity-building, mentoring and training have been highly successful in strengthening cancer control in other $\mathrm{LMICs}^{39}$.

\section{Limitations}

Page 21/27 
It is important to note that some countries were represented by fewer than four stakeholders. While this is in part reflective of the low number of individuals working in cancer control in some areas (e.g. Tonga, Samoa); it is predominantly the result of the limited six-week data collection time-frame.

\section{Conclusion}

A regional cancer control Coalition for the South Pacific is both wanted and feasible. If momentum is continued, and a regional South Pacific Coalition established following the findings and recommendations from this project, the benefits in reducing the burden of cancer within the region will be substantial. Further, our results describe the effective implementation of a Coalition Development Framework in an applied setting.

\section{Declarations}

\section{Ethics approval and consent to participate}

Ethics approval was sought and granted through Melbourne University School of Population and Global Health Human Ethics Advisory Group (ID: 1955207.1).

\section{Consent for publication}

Not applicable.

\section{Availability of data and materials}

The datasets generated and/or analysed during the current study are not publicly available as maintaining privacy and confidentiality of both qualitative and quantitative data generated via coalition consultations was a condition of consent.

\section{Competing interests}

The authors declare that they have no competing interests.

\section{Funding}

The majority of this work was completed as part of a Masters of Public Health student project. Funding to facilitate travel in the Pacific and miscellaneous research costs was provided by Cancer Council Australia.

\section{Authors' contributions}

SA, BC, CB, and SB conceived the study. Study design, methods and project planning was completed by all authors. $\mathrm{AH}$ and $\mathrm{BC}$ undertook data collection. $\mathrm{AH}$ analysed the data and drafted the publication. RM and SA reviewed data analysis. All authors read and approved the final manuscript. 
Acknowledgements

The authors wish to thank all participants for their generosity and time in facilitating this study.

\section{References}

1. Bray F, et al. Global cancer statistics 2018: GLOBOCAN estimates of incidence and mortality worldwide for 36 cancers in 185 countries. Cancer J Clin. 2018;68(6):394-424.

2. Sarfati $D$, et al. Cancer control in small island nations: from local challenges to global action. The Lancet Oncology. 2019.

3. Tervonen $\mathrm{H}$, et al. Cancer epidemiology in the small nations of Pacific Islands. Cancer epidemiology. 2017;50:184-92.

4. Sarfati $D$, et al. Cancer control in the Pacific: big challenges facing small island states. The lancet oncology. 2019;20(9):e475-e92.

5. Foliaki S, et al. Cancer control in the Pacific: a South Pacific collaborative approach. Cancer Epidemiol. 2017;50:193.

6. Foliaki S, et al. Cancer incidence in four pacific countries: Tonga, Fiji Islands, cook Islands and Niue. Pac Health Dialog. 2011;17(1):21-32.

7. Varghese $\mathrm{C}$, et al. Cancer burden and control in the Western pacific region: challenges and opportunities. Annals of global health. 2014;80(5):358-69.

8. Crouch-Chivers PR. A review of cancer in Papua New Guinea. P N G Med J. 2010;53(1/2):48.

9. Mialon $\mathrm{M}$, et al. Analysis of the corporate political activity of major food industry actors in Fiji. Globalization health. 2016;12(1):18.

10. Snowdon W, et al. Non-communicable diseases and health system responses in Fiji. Melbourne: The Nossal Institute, University of Melbourne; 2013.

11. Shin H-R, et al. Cancer control in the Asia Pacific region: current status and concerns. Jpn J Clin Oncol. 2012;42(10):867-81.

12. Latu $\mathrm{R}$, et al. Cancer control in resource-limited settings. Pacific Journal of Reproductive Health. 2016;1(3).

13. Dain K. Challenges Facing Global Health Networks: The NCD Alliance Experience: Comment on" Four Challenges that Global Health Networks Face". International journal of health policy management. 2018;7(3):282.

14. Walker J, et al. Medicine shortages in Fiji: A qualitative exploration of stakeholders' views. PLoS One. 2017;12(6):e0178429.

15. Olver I. Cancer control-a global perspective. Eur J Cancer Care. 2017;26(1):e12654.

16. Kim E, et al. Cost-benefit analysis of establishing and operating radiation oncology services in Fiji. Cancer epidemiology. 2017;50:247-56. 
17. Pearlman PC, et al. Multi-stakeholder partnerships: breaking down barriers to effective cancer-control planning and implementation in low-and middle-income countries. Sci Dipl. 2016;5:1-15.

18. Youlden DR, et al. Incidence and mortality of female breast cancer in the Asia-Pacific region. Cancer biology medicine. 2014;11(2):101.

19. Tsu VD, et al. The investment case for cervical cancer elimination. International Journal of Gynecology Obstetrics. 2017;138(S1):69-73.

20. Bollars $\mathrm{C}$, et al. Exploring health literacy in relation to noncommunicable diseases in Samoa: a qualitative study. BMC Public Health. 2019;19(1):1151.

21. Lilo, LSu, et al. Health literacy, culture and Pacific peoples in Aotearoa, New Zealand: A review. Pacific Health. 2020;3.

22. Alexander JA, et al. Challenges of capacity building in multisector community health alliances. Health Education Behavior. 2010;37(5):645-64.

23. Hassell TA, et al. Civil society promoting government accountability for health equity in the Caribbean: The Healthy Caribbean Coalition. Revista Panamericana de Salud Pública. 2020;44.

24. Dunn J, et al. Engaging NGOs in national cancer-control efforts. The Lancet Oncology. 2013;14(11):1044-6.

25. Palafox NA, et al. Comprehensive cancer control planning in the Pacific: the Cancer Council of the Pacific Islands a multi-national regional coalition. Cancer Causes Control. 2018;29(12):1287-95.

26. Nitta $M$, et al. Cancer risk reduction in the US Affiliated Pacific Islands: Utilizing a novel policy, systems, and environmental (PSE) approach. Cancer epidemiology. 2017;50:278-82.

27. Palafox NA, et al. A socio-ecological framework for cancer control in the Pacific: a community case study of the US affiliated Pacific Island jurisdictions 1997-2017. Frontiers in public health. 2018;6:313.

28. Palafox NA, et al. Pacific Island Partnership: The Pacific Cancer Initiative. Journal of Cancer Education. 2006;21.

29. NCD Alliance (NCDA). Practical guide on how to build effective national and regional NCD alliances. Available online: https://ncdalliance.org/news-events/news/new-practical-guide-on-how-to-buildeffective-ncd-alliances.

30. De Silva MJ, et al. Theory of Change: a theory-driven approach to enhance the Medical Research Council's framework for complex interventions. Trials. 2014;15(1):267.

31. Blomkamp E. The Promise of Co-Design for Public Policy. Australian Journal of Public Administration. 2018;77(4):729-43.

32. Sugawara Y, et al. Cancer patients on Twitter: a novel patient community on social media. BMC Research Notes. 2012;5(1):699.

33. Thorne S. Interpretive description: Qualitative research for applied practice. Routledge; 2016.

34. Braun KL, et al. Empowerment through community building: Diabetes Today in the Pacific. Journal of Public Health Management Practice. 2003;9:19-25. 
35. Anderson BO, et al. Breast cancer in limited-resource countries: health care systems and public policy. The breast journal. 2006;12:54-69.

36. Ekeroma A, et al. Cancer management in the Pacific region: a report on innovation and good practice. The Lancet Oncology. 2019;20(9):e493-502.

37. King NB, et al. Defining global health as public health somewhere else. BMJ Global Health. 2020;5(1).

38. Chasek PS. Margins of power: Coalition building and coalition maintenance of the South Pacific island states and the alliance of small island states. Rev Eur Comp Int'l Envtl L. 2005;14:125.

39. Ngwa W, et al. The Use of Health-Related Technology to Reduce the Gap Between Developed and Undeveloped Regions Around the Globe. American Society of Clinical Oncology Educational Book. 2020;40:227-36.

\section{Figures}

\section{Engagement}

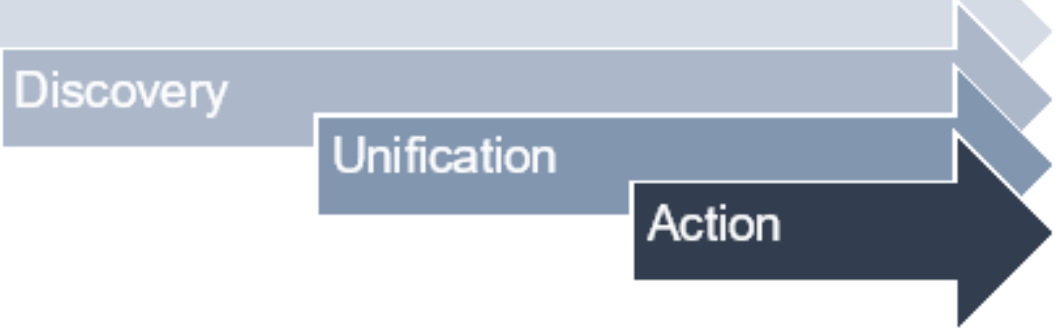

\section{Figure 1}

Coalition Development Framework Phases 


\section{South Pacific Cancer Control Coalition Themes}

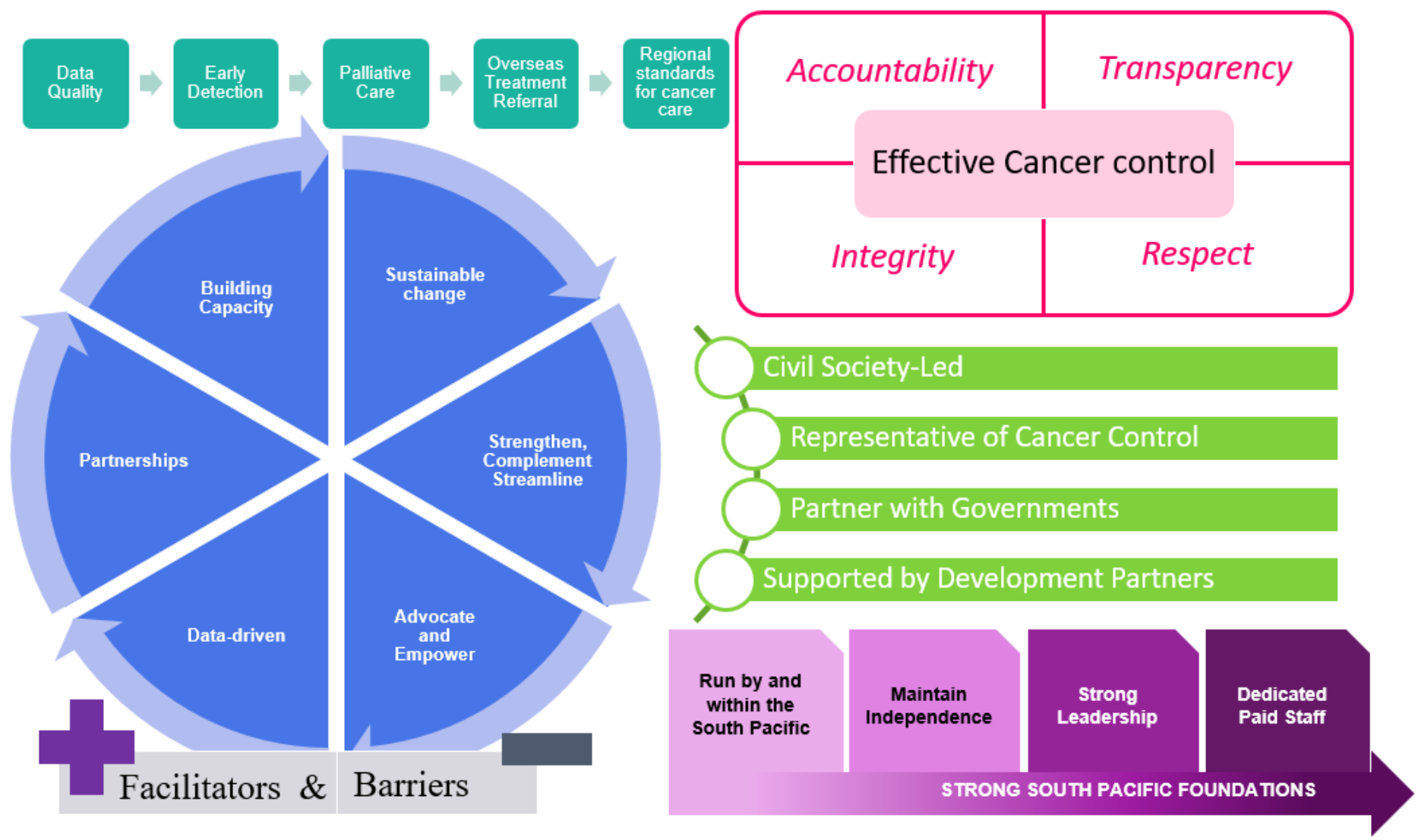

Figure 2

Composite of Coalition Development Themes 


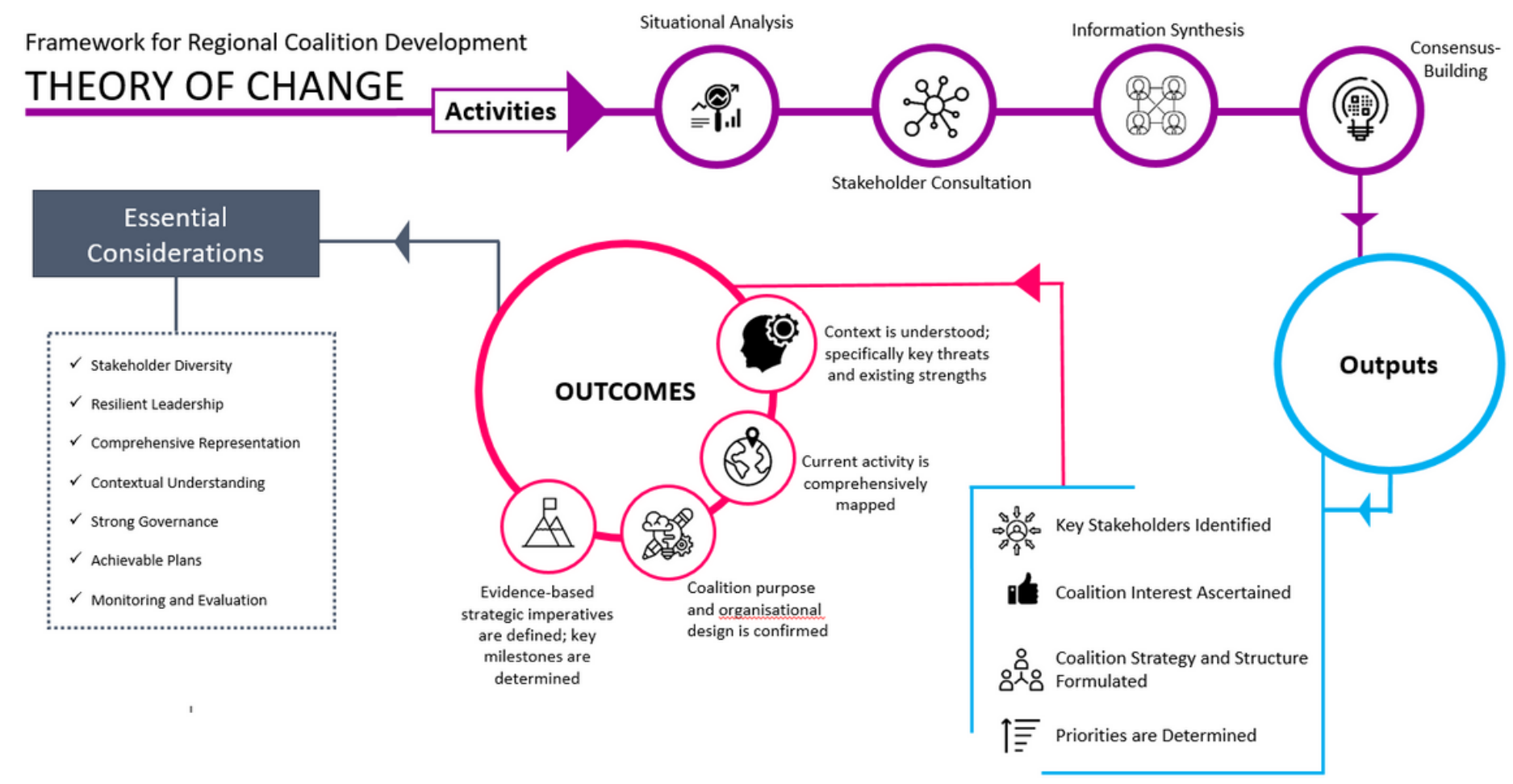

\section{Engagement}

\section{Figure 3}

Evaluation of the proposed Coalition Development Framework 